\title{
Evaluation of Cruise Ship Supply Logistics Service Providers with ANP-RBF
}

\author{
Liling Huang $\left(\mathbb{D},{ }^{1}\right.$ Yong Tan $\mathbb{D}^{1},{ }^{1}$ and Xu Guan ${ }^{2}$ \\ ${ }^{1}$ School of Management, Wuhan Polytechnic University, Wuhan 430048, China \\ ${ }^{2}$ School of Management, Huazhong University of Science and Technology, Wuhan 430074, China \\ Correspondence should be addressed to Liling Huang; huangliling@whpu.edu.cn and Yong Tan; 11857985@qq.com
}

Received 22 December 2020; Revised 29 April 2021; Accepted 19 May 2021; Published 29 May 2021

Academic Editor: Yong Wang

Copyright (C) 2021 Liling Huang et al. This is an open access article distributed under the Creative Commons Attribution License, which permits unrestricted use, distribution, and reproduction in any medium, provided the original work is properly cited.

To overcome challenges like market dynamic configuration, information integration, and quick response, it is necessary to build an efficient, stable, and well-coordinated supply chain relationship for cruise ship supply. This requires building of a solid evaluation index system of logistics service providers (LSPs) in the cruise ship supply chain. In this paper, we introduce an evaluation index system that consists of four dimensions, based on the characteristics of cruise ship supply and the connotation and type of cruise ship supply LSPs. The four dimensions are business level, collaborative capacity, service price, and information level, including ten subcriteria. We first establish an evaluation decision model for the interdependence and feedback relationship between the criteria by using analytic network process (ANP) for weight definition of each index; then, we use Super Decisions software to simulate the results, combine RBF neural network training and validation, and extract implicit knowledge and laws. We propose an incremental algorithm that can effectively avoid the influence of subjective factors and increase the dynamic nature of evaluation. The results show that the ANP-RBF method has strong practicability in the evaluation of cruise ship supply LSPs.

\section{Introduction}

Since the end of the 20th century, the international cruise tourism industry has developed rapidly, with an average annual growth rate of $8 \%-9 \%$, ranking the fastest in the global tourism market. As the growth of cruise economic throughout the world continues to lead to the problem of cruise ship supply chain, solutions to supply chain issues of supporting facilities planning, marketing mix customer satisfaction, and logistics supply process are becoming increasingly urgent [1]. The majority of previous research studies had focused on supporting facilities planning and logistics supply process, while limited attention had been paid to partnership issues [2-4]. However, partnership issues are becoming more and more urgent as partnership selection quantity has increased rapidly owing to the explosive growth of global purchasing. Cruise ship supply chain has some unique characteristics such as complexity, time validity, irreversibility, and high supply variability [5]. The time of a cruise port calling is limited, and there are only a few hours for cruise ship replenishment on a tight schedule. The cruise ship supply includes local procurement and overseas procurement, with the supplies being of various varieties and large amount. Therefore, the cruise ship supply chain needs an efficient, stable, and well-coordinated supply chain relationship. It can overcome challenges like dynamic market configuration, information integration, and quick response. The outsourcing of cruise ship logistics service is conducive for the cruise companies to maintaining a stable source of goods and prices. To a certain extent, this can ensure quality [6]. In recent years, the upsurge of cruise tourism has promoted the development of cruise ship supply logistics. An appropriate evaluation of LSPs is an important step towards creating successful alliance and avoiding failure of relationships afterwards. Because the cruise industry is emerging industry, the evaluation of cruise ship supply LSPs has become an urgent problem for decision makers of cruise companies.

Traditional LSPs evaluation has focused on providing a low price and high quality. However, these can no longer be 
met owing to the unique characteristics of cruise. To solve this problem, the evaluation of cruise ship supply LSPs should consider the characteristics of cruise ship supply. Otherwise, unrealistic criteria can hardly contribute to handling the problem.

This study focuses on partnership evaluation problem. An index system will be useful for the determination of the cruise ship supply LSPs. Without reliable evaluation results of the index system, it will be difficult for the partnership resources in cruise ship supply to remain stable. As a result, it will become occasionally difficult to ensure efficiency and quality owing to the lack of organization and management. At the same time, some tourists will be lost as a result of the unbalanced cruise service.

This paper enriches the field of cruise ship supply logistics management by making the following contributions. First, we put forward the special research perspective and objects. Cruise tourism is an emerging industry in China, and the research on its operation process supply chain is the current research trend. However, there is little research on the index system of cruise ship supply LSPs. This paper introduces the evaluation study of LSPs into the specific field of cruise industry. Second, we analyze the characteristics of cruise ship supply and further construct the index system. It fills the gap that deals with provider evaluation index of cruise ship supply chain. Finally, this study recognizes the requirement of diversified expertise both on technical and domain knowledge for making a right decision, proposing to use this expertise in group decision-making; it is of great practical significance to realize the planning of the cruise ship supply industry chain, improve the efficiency of the cruise ship supply chain, and realize the stable and healthy development of the cruise economy.

The remainder of this paper is organized as follows. In Section 2, we survey a relevant literature review from cruise ship supply and LSPs evaluation. In Section 3, we introduce definition and types of service supply chain to cruise ship supply and build the evaluation index system from four dimensions and ten subcriteria. Then, Section 4 presents the method. Later, Section 5 gives a numerical example to verify the evaluation method. Eventually, Section 6 concludes this article and suggests possible research directions in the future.

\section{Literature Review}

This paper will address LSPs evaluation problem of the cruise ship supply through cruise ship supply chain, and LSPs evaluation methods.

In terms of cruise ship supply chain, most of research is macroscopic. For example, Véronneau and Roy analyzed the planning process of the cruise supply chain and proposed that the cruise operation focused on logistics supply [7]. Due to the characteristics of cruise supply point movement, the distance between the port of call and the raw material supply point further increased the lead time of supply [6]. According to Boyd tactical cycle theory, replenishment lead time should be shorter than cruise length to maintain the responsiveness within a certain period. Shortening the delivery time was the main solution to provide more flexibility, and this was further transferred to the pull supply system [8]. Furthermore, with the large-scale development of cruise ships, ship tonnage and passenger capacity gradually increase, which brings many challenges to cruise ship operation management [9]. The distribution problem of cruise ship supply, which had the characteristics of large quantity, high value, and strict time requirement, required specialized cruise distribution centers and supporting facilities to centralized procurement, centralized supervision, centralized distribution, and centralized settlement for the distribution development. It was proposed that if a port could provide comprehensive cruise logistics service for international cruise lines, such as complete port facilities, transport buildings, supplies services, and integrate related industries, the port is promoted as the cruise logistics service hub $[10,11]$.

LSPs selection and optimization are the source of the construction of service supply chain to cruise ship supply. Besides, the evaluation of LSPs includes supplier quantity optimization decision, supplier evaluation, and logistics task allocation, which is a typical multiobjective decision-making problem [12]. In the existing literature, many works are devoted to the evaluation of LSPs at domestic and foreign level. For example, Ding, Kuo, and Tai [13] use the fuzzy analytic hierarchy process (AHP) method to empirically study the key competency and capabilities affecting the selection of middle managers for global shipping logistics service providers (GSLSPs). Jain and Khan [14] formulated the reverse logistics service provider selection as a multicriteria decision-making problem and developed a methodology to select the best two reverse logistics service providers for an injection moulding parts manufacturer company using analytical hierarchy process (AHP). Thirdparty logistics service providers (3PLSPs) evaluation and selection for a long-term as well as a strategic partnership constituted a very crucial and critical task, and they were continually associated with uncertain challenges. In order to measure and compare the relative efficiency of the existing 3PLSPs based on the technical and sustainable criteria, a data envelopment analysis (DEA) was used to find the best among the 3PLSPs portfolios, for the purpose of selection [15]. Celik, Erdogan, and Gumus [16] determined the criteria of green logistics service providers, and the criteria weights were determined by fuzzy AHP, based on expert opinions. Then, a new method was proposed, which was the combination of fuzzy TOPSIS and GRA, and used to evaluate green 3PLs based on different separation measures, Chen, Yu, and Yang [17] established an evaluation index system for the reverse logistics service provider selection and proposed a new multiattribute decision-making method, GITOPSIS, based on combinational weight determination. In terms of weight determination, they combined ANP with entropy method to consider the dependency of evaluation indexes and the information of evaluation data; then, they introduced the degree of grey incidence into TOPSIS and used relative similarity degree to reflect the distance differences and shape changes. Seongtae, Ramkumar, and Subramanian [18] focused on an assessment framework that 
combines two MCDM techniques: decision-making trial and evaluation laboratory (DEMATEL) based analytic network process (ANP) (hereafter "DANP") and complex proportional assessment of alternatives to grey relations (COPRASG) technique. Abdel-Baset et al.[19] provided a multicriteria group decision-making (MCGDM) proposed technique of the ANP (analytical network process) method and the VIKOR (ViseKriterijumska Optimizacija I Kompromisno Resenje) method under neutrosophic environment for dealing with incomplete information and high order imprecision.

From the perspective of research content, domestic and foreign scholars have gradually deepened their research on cruise ship supply, ranging from planning process to supporting facilities on board. In addition, the research on cruise ship supply is limited to the form of summary, and a good relationship is essential in cruise ship supply chain. The research on the evaluation of LSPs mainly focused on the selection and evaluation of third-party logistics enterprises. However, China cruise tourism is still in its infancy, and the development of the cruise industry is not yet perfect. In parallel to the increasing trend in LSPs evaluation research literature towards analyzing method, model, and related problems, the evaluation of cruise ship supply LSPs emerges as one of the appealing research topics in this area, and there are few related empirical studies. For example, from the six aspects of supply quality, price, service, technology, and competition, the supplier evaluation index system of cruise companies was established under the supply chain management environment [20]. The deployment problem of the liner ship fleet with uncertain demand was different from other logistics problems with uncertain demand [21, 22].

Generally, such a problem is an issue of great concern to decision makers. Most of relevant research studies on LSPs evaluation ignored integration, personalization, and network demand features of the logistics service chain. Therefore, the innovation of this paper is based on previous studies; an evaluation index system of cruise ship LSPs is constructed from the perspective of the features, connotation, and types of cruise ship supply LSPs.

From the viewpoint of research methods, overall, the research methods of LSPs evaluation include qualitative method, quantitative method, and both of them. Moreover, the common methods are AHP, DEA, TOPSIS, ANN, ANP, and the combination of these methods [23-30]. Generally speaking, these methods have different principles, and each has its own advantages and disadvantages in solving practical problems, as shown in Table 1.

Through the above summary, we find that each method has advantages and shortcomings, and there are three characteristics in the research of provider selection methods. First, AHP and DEA are most widely used; second, two or even three different methods are used comprehensively to solve the problem of supplier selection as objectively and accurately as possible; third, new intelligent methods become a research trend. The traditional AHP method cannot fully meet the needs of this study, because the relationship between the evaluation indexes of cruise ship LSPs is not nonlinear and independent. The ANP method is the development and extension of the AHP. Therefore, we choose to apply ANP method due to the characteristics of mutual feedback and connection among the indexes, and Super Decisions software is used for its shortcoming. At the same time, the evaluation of cruise ship supply LSPs is a typical multiattribute decision group evaluation problem. After comparing other LSPs evaluation methods, the ANP method can take into account the characteristics of the relevance between all indexes and realize weight to each index. We propose an incremental algorithm that can effectively avoid the influence of subjective factors in ANP method, increase the dynamic nature of evaluation, combine RBF neural network training and validation, and extract implicit knowledge and laws. The combination of ANP and RBF method will make the weight more objective and scientific, and this method is feasible and practical.

\section{Evaluation Index System}

3.1. Definition and Types. Cruise ship supply, namely, material supply for cruise liner, in a broad sense, refers to the supply of food, beverage, liquor, fuel, hotel supplies and equipment, and navigation and communication equipment offered to customers in cruise liner operations. In a narrow sense, cruise ship supply refers to the supply of food and daily necessities used and consumed by cruise crew and passengers during the voyage. Specifically, cruise ships provide food for passengers and crew during the voyage, such as fresh fruits and vegetables, meat products, and fresh water; the cruise ship also involves daily necessities like toiletries and bed sheets [31]. In order to cater the diversified consumption demands of cruise passengers from all over the world, cruise companies purchase different flavors of food from different countries to achieve a five-star experience. There is also the need for international cruise ships to meet the high standards of five-star hotels and provide first-class services. At present, there are more than 60 cruise ships with more than 100000 gross tonnage, which can carry 2500 passengers and crew. And there are many giant cruise ships that can carry 8800 passengers and crew. For example, ocean symphony is the largest cruise ship in the world with 18 decks, 22 restaurants, 24 swimming pools, 2759 guest rooms, and other entertainment facilities; it can be called a maritime city. In the next ten years, there will be 40 giant cruise ships on cruise market. The large scale of ship size and the large quantity of passengers would bring huge demand for cruise ship supplies.

Compared with the supply of ordinary cargo ships, the purchase of cruise ship supplies has the following characteristics:

(1) Global Procurement. Compared with ordinary cargo ships, cruise ships carry a large number of passengers. For example, there are more than 8,000 people in the quantum of the sea, which needs a large number of living materials and other spare parts. In order to ensure quality and reduce procurement cost, cruise ship supplies are purchased all over the world.

(2) High Supply Frequency. Cruise ships usually have a period of several days or weeks to realize the cycle of 
TABLE 1: Summary of LSPs evaluation methods.

\begin{tabular}{|c|c|c|}
\hline Method & Advantages & Shortcomings \\
\hline AHP & $\begin{array}{l}\text { It can simplify complex problems; there are few } \\
\text { requirements for quantitative data information. }\end{array}$ & $\begin{array}{l}\text { It is too subjective, and too many indexes will lead to large } \\
\text { data statistics and uncertain weight. With the increase of } \\
\text { indexes, the accurate calculation of eigenvalues and } \\
\text { eigenvectors will be more complex. }\end{array}$ \\
\hline DEA & $\begin{array}{l}\text { It selects high quality suppliers by measuring the } \\
\text { relative efficiency of evaluation objects, and it is simple } \\
\text { to apply. }\end{array}$ & $\begin{array}{l}\text { It is usually a subjective value determined in advance and } \\
\text { specific to a certain degree of randomness. }\end{array}$ \\
\hline TOPSIS & $\begin{array}{l}\text { It requires less sample data and is easy to understand } \\
\text { and simple to operate. }\end{array}$ & $\begin{array}{l}\text { The distance as a scale can only reflect the position } \\
\text { relationship between data curves and cannot reflect the } \\
\text { dynamic changes of data series. }\end{array}$ \\
\hline BP neural network & $\begin{array}{c}\text { It can solve any complex nonlinear problems and has } \\
\text { the ability to self-learn and self-adapt. }\end{array}$ & $\begin{array}{l}\text { It has low learning efficiency and slow convergence speed, } \\
\text { is easy to fall into local minimum state, and so on. }\end{array}$ \\
\hline $\begin{array}{l}\text { Fuzzy } \\
\text { comprehensive } \\
\text { evaluation }\end{array}$ & $\begin{array}{c}\text { It is simple and easy to understand, and the evaluation } \\
\text { effect is ideal for complex problems with multiple } \\
\text { indexes and multiple levels. }\end{array}$ & $\begin{array}{l}\text { The calculation of the weight of each index is highly } \\
\text { subjective, and it is difficult to determine the membership } \\
\text { function. }\end{array}$ \\
\hline $\begin{array}{l}\text { Grey relational } \\
\text { analysis }\end{array}$ & $\begin{array}{l}\text { The grey information and white information are } \\
\text { treated differently, which can ensure the integrity and } \\
\text { accuracy of information; they do not need many } \\
\text { samples and normalization processing. }\end{array}$ & $\begin{array}{l}\text { The theoretical basis is relatively narrow, the } \\
\text { standardization lacks comprehensiveness, and it is unable } \\
\text { to deal with the information duplication caused by relevant } \\
\text { indicators. }\end{array}$ \\
\hline ANP & $\begin{array}{l}\text { An interactive risk evaluation system is incorporated } \\
\text { into the supplier selection process. The triangular } \\
\text { fuzzy number is used to construct the linguistic } \\
\text { evaluation set to avoid the negative impact of } \\
\text { subjective judgment. }\end{array}$ & $\begin{array}{l}\text { It is a very complex operation process to solve the } \\
\text { hypermatrix problem. }\end{array}$ \\
\hline
\end{tabular}

departure and return. Compared with freighters, materials are consumed quickly and need to be replenished in a short time. Besides, cruises are often berthing, and frequent replenishment and formalities are required in cruise ports.

(3) The cruise lines purchase directly from the suppliers, while the cargo ships purchase from the agent companies.

(4) The standard of cruise ship supplies is uniform, and supplies are high-end, differentiated, and centrally sourced. The supply system should be stable, and food should be secure.

Cruise ship supply logistics refers to a series of logistics activities, such as storage, transportation, loading and unloading, processing, packaging, information processing, and distribution in the process of material flow from manufacturer/ship supplier to cruise ship. Due to the mobility and tourism properties of cruise ships, cruise ship supply logistics is more complex than general logistics. In the general sense, LSPs are not traditional logistics services providers for cruise ship supply, but suppliers that provide operational logistics services for the core cruise enterprises in the cruise ship supply chain, that is, functional LSPs, including LSPs of transportation, storage, distribution, and customs clearance, which act as upstream service providers of the cruise enterprise in the ship supply chain and provide the logistics service with its core advantages. In addition, they have established a long-term strategic cooperative relationship with the port enterprises, which is also the most fundamental feature different from traditional LSPs.

The service supply chain of cruise ship supply is a kind of capability cooperation, which takes cruise ship as the core enterprise and integrates other types of cruise ship LSPs. According to the types of cruise ship supply LSPs, the functional LSPs of cruise ship supply could be divided into single type and composite type: the single type is LSPs that only provide single logistics service capability, such as warehouse operators or distributors; the composite type is LSPs that provide multiple logistics service capabilities simultaneously. For example, the third-party integrated logistics enterprise could provide a variety of service capabilities such as transportation, storage, and distribution. The composite type of LSPs is studied on cruise ship supply chain in this paper.

3.2. Evaluation Index System Construction. Most of the existing evaluation index systems of LSPs only studied capability evaluation of LSPs in the traditional supply-demand management mode, such as quality, delivery time, and cost. However, they cannot fully reflect the requirements of LSPs in supply chain management mode. Hence, they cannot adapt to the global characteristics of the cruise ship supply chain, and the strategic partnership of information sharing and risk sharing cannot be realized. Meanwhile, a long-term, stable, and it is necessary to establish sustainable strategic partnership between the cruise ship supply LSPs and the port enterprises, so the evaluation of the collaborative ability should not be ignored for LSPs of cruise ship supply, which would affect the stable and benign operation of the whole logistics service supply chain. Besides, there is a lack of evaluation at the information level of LSPs in many index systems. In the network economy environment, the response time and the personalization degree of supply chain are closely related to information. In the mature evaluation of 
LSPs, information level is an important prerequisite to ensure the success and stability of cooperation. Numerous available studies provide information on the evaluation criteria to be chosen for the cruise ship supply LSPs. Hence, while cruise companies select LSPs for cruise ship supply, they should evaluate them from the perspective of the whole logistics service supply chain, which should not only investigate the service price and business level of LSPs, but also pay attention to their synergies and competitiveness with upstream and downstream members.

When establishing the evaluation index system for cruise ship supply LSPs, we should pay attention to the following principles.

(1) Simplicity. The evaluation index should be simplified, focused, and easy to operate

(2) Independence. There is no inclusion relationship between all levels of evaluation indexes in the index system

(3) Scientificity. The actual situation should be accurately reflected so that cruise companies can make an objective and comprehensive evaluation of shipping LSPs

(4) Generality. The established index system should reflect the commonness of cruise ship service providers

In this paper, we establish an index system from the characteristics of cruise ship logistics service. It comprehensively reflects what cruise enterprises should consider in the evaluation of LSPs.

3.2.1. Service Price. In the traditional supply chain, price is often an important index for enterprises to select and evaluate suppliers. Besides, price is also an important index that cannot be ignored in the field of service supply chain $[32,33]$. An effective price control can enhance the competitiveness of the whole service supply chain for cruise companies. The service price of LSPs mainly includes three indexes: The first is the transportation cost [34], because cruise ship supplies are mainly global sourcing. The second is cost elasticity, including storage costs, handling costs, sorting costs, handling expenses, sorting costs, and packing costs; it can reflect not only the coordination of the logistics links, but also the operation of the supply chain. The third is logistics supporting facilities; it directly affects the quality of logistics services.

3.2.2. Business Level. A strong business level is the guarantee for high quality services to LSPs. It mainly includes two aspects: The first is on-time delivery; cruise ship supplies are mostly consumables for people on board, the supply volume is huge in a short time, and most of them belong to refrigerated and fresh-keeping food. Therefore, they require high timeliness, and the cruise liner has a short replenishment time at home port and midway port, so LSPs should deliver the supplies to the cruise ships in the short time window; otherwise, the loss of shortage cost is immeasurable
[28]. The second is logistics network; due to mobility and irreparability of cruise ship supply logistics, it needs professional logistics parks, logistics nodes, transport channels, and distribution facilities [35]. Besides, logistics network plays an important role in supply chain, and the optimization of logistics network would affect the logistics service level and cost of providers [36-41].

3.2.3. Collaborative Capacity. Collaborative capacity is the collaboration ability of LSPs in the process of cooperation with port enterprises, government enterprises, and other LSPs, which is mainly reflected in the communication and coordination ability and cooperation efficiency of LSPs. $[6,7]$. Hence, it can be embodied from the three aspects of supply time flexibility, risk response ability, and collaborative development capability [42-44].

\subsubsection{Information Level. Cruise ship supply chains are} global and are composed of a variety of products and streams, which render the process of tracking burdensome. Visibility of the production transit is essential to keep track of replenishment in this "just-in-time" environment. Hence, information level can highlight the advantages of LSPs and ensure the irreplaceable role in the cruise ship logistics service. Information investment and system integration capability reflect the informatization level of LSPs to some extent; for example, the information service system, realtime monitoring, cargo access, and passenger flow separation can ensure the smooth operation of the goods and tourists required for the cruise liner [5, 7]. Information level can guarantee the accuracy and timeliness of information communication between ship supply LSPs and port enterprises, to improve the cooperation efficiency and maintain a long-term and stable cooperative relationship.

Based on the above analysis, we can construct the evaluation index system of cruise ship supply LSPs, as shown in Table 2.

\section{Methods}

There are many factors affecting the evaluation of cruise ship service providers. For ease of analysis processing, we choose a limited number of representative indexes to evaluate and analyze according to the unique characteristics of cruise ship logistics service industry in this paper. In addition, because of the certain mutual relationship and influence among the indexes in the logistics system, we apply the analytic network process (ANP) to ascertain the weights of indexes. Meanwhile, in order to avoid the influence of subjective factors in the decision-making process by using ANP model, we use integrated ANP and RBF neural network to evaluate cruise ship supply LSPs.

4.1. The Analytic Network Process. Analytic Network Process (ANP) is a decision-making method proposed by Professor Thomas L Saaty, Professor of University of Pittsburgh, Pennsylvania, in 1996. It is suitable for nonindependent 
TABLE 2: Dimensions and subcriteria for cruise ship LSPs.

\begin{tabular}{lcc}
\hline Dimensions & Criteria & Reference \\
\hline Business level (B1) & On-time delivery (C1) & Véronneau and Roy (2009) [5]; Vukonic, Bielic, and Russo (2016) [9] \\
& Logistics network (C2) & Budiartha and Adnyana (2016) [22] \\
Information investment (C3) & Véronneau and Roy (2009) [5], [7] \\
Information level (B2) & System integration capability & (C4) \\
& Supply time flexibility (C5) & \\
Collaborative capacity & Risk response ability (C6) & Véronneau, Roy, and Beauieu (2015) [6]; Véronneau and Roy (2009) [7]; \\
(B3) & Collaborative development & Erkoc, Iakovou, and Spaulding (2005) [42] \\
& capability (C7) & \\
Cost elasticity (C8) & Transportation cost (C9) \\
Service price (B4) & Logistics supporting facilities & Regina Galo et al. (2018) [25]; Mohamed et al. (2020) [34] \\
&
\end{tabular}

"hierarchy structure" [24]. Based on the traditional linear analytic hierarchy process (AHP), which considers the interrelation and internal dependence of each factor, the network form is used for elaboration and development, and then the objectives of organization and its optimal weight value are confirmed systematically for reaching decisions. The specific steps are as follows:

Step 1: establishing the hierarchical structure of decision issues. The decision-making system can be divided into two parts by ANP: The first part is the control layer, which confirms the goal according to the nature of the problem. Then, through literature analysis, this study selects the decision-making dimensions and subcriteria and establishes the hierarchical structure of decisionmaking. All the decision-making criteria are considered to be independent of each other and only controlled by the objective factors. The weight of each criterion can be ascertained by ANP. The second part is the network layer, which is composed of all the elements dominated by the control layer. The inner part is the network structure of mutual influence. The elements depend on and dominate each other, and the inner part of the elements and the layers are independent of each other. Each criterion dominates a pair of interdependent and feedback network structures in the hierarchical structure. In this study, decision-making experimental analysis method is used to establish the external dependence of the structural layer and the internal and external dependence of the criteria. Finally, ANP network hierarchy diagram is established according to all the influence relationships (network layer) and hierarchy.

Step 2: designing and filling the ANP questionnaire. After the establishment of ANP network hierarchy in step 1, an ANP questionnaire is made according to the internal and external dependence between dimensions and subcriteria. The content of the questionnaire can be divided into three parts: the first part is the comparison of the relative importance of evaluation criteria under the dimensions or levels for the structural layer; the second part is the comparison of the dependence ratio between the dimensions of the structural layer; and the third part is the comparison of the dependence between the evaluation criteria. In any part, the format is a paired comparison of two elements. In the part of evaluation scale, Saaty (1980) divided the evaluation scale into four levels, with a nominal 1-9 scale representing nine categories from "equal importance" to "absolute importance."

Step 3: constructing the pairwise comparison matrix. The pairwise comparison matrix is the pairwise comparison between the structural layer and the criterion layer, respectively. Under certain factors of each network hierarchy, the relative importance of pairwise comparison is measured by using the name scale as the ratio. The ratio is the constituent element of the constructed comparison matrix, as shown in the following formula:

$$
X=\left[x_{i j}\right]_{n \times n}=\left[\begin{array}{cccc}
1 & x_{12} & \cdots & x_{1 n} \\
x_{21} & 1 & \cdots & x_{2 n} \\
\vdots & \vdots & \ddots & \vdots \\
x_{n 1} & x_{n 2} & \cdots & 1
\end{array}\right]_{n \times n}
$$

where $\quad x_{i j}=1 / x i j\left\{\right.$ when $i \neq j, x_{i j}=[1 / 9,1 / 8$, $1 / 7,1 / 6,1 / 5,1 / 4,1 / 3,1 / 2,1,2,3,4,5,6,7,8,9]$, when $i=$ $j, x_{i j}=1, i=1,2, \ldots, n, \quad j=1,2, \ldots, n$.

Step 4: eigenvalues and eigenvectors. Normalization of the geometric mean of the rows (NGM) method is adopted, which is a method of calculating eigenvectors proposed by Saaty (1980). The geometric mean of matrix column vectors is standardized, geometric average is shown in (2), and eigenvalue and eigenvalue vector can be defined as

$$
\begin{aligned}
g_{c n} & =\sqrt[n]{1 \times a_{12} \times \cdots \times a_{1 n}}, \\
w_{X n} & =\frac{g_{c n}}{G}{ }_{n}{ }_{y=1} g_{c y}, \quad 1=\sum_{y=1}^{n} w_{x y}, \\
G & =\sum^{n}
\end{aligned}
$$




$$
w_{i}=\left[\begin{array}{c}
w_{X 1} \\
w_{X 2} \\
\vdots \\
w_{X n}
\end{array}\right] .
$$

Step 5: consistency test. The consistency of the results of the comparison matrix is tested, and the consistency index and the consistency ratio are compared in pairs to determine whether there is unreasonable judgment and whether the degree of decision-making is consistent.

The consistency ratio $(C R)$ is derived from the consistency index $(C I)$ divided by random variables $R I$, as shown in

$$
\begin{aligned}
C I & =\frac{\lambda_{\max }-n}{n-1}, \\
C R & =\frac{C I}{R I} .
\end{aligned}
$$

The larger the value of $C I$ is, the greater the deviation of the judgment matrix from the complete consistency is; the smaller the value of $C I$ is (close to 0 ), the better the consistency of the judgment matrix is. When the judgment matrix is completely consistent, $C I=0$; when the judgment matrix is satisfactory consistent, the average random consistency index value, $R I$, of the judgment matrix should be introduced.

If the order is greater than 2 , the ratio of the consistency index, $C I$, of the judgment matrix to the average random consistency index, $R I$, is called the random consistency ratio, $C R$; if $C R \leq 0.10$, it can be considered that the judgment matrix is satisfactorily consistent; otherwise, it needs to be adjusted.

Step 6: constructing the super matrix.

Step 7: building the limit super matrix to ascertain the index weight value.

4.2. RBF Neural Network. Radial basis function (RBF) neural networks, being inherited from the perceptual model on visual hyperacuity, are well-known for the simple topological structure and universal approximation ability. Since the approximation ability has been proved, they have drawn much attention to various areas, such as classification, nonlinear system modeling, and adaptive control [45-47]. Nevertheless, RBF neural networks still face challenges and open problems on how to model nonlinear systems accurately and fast $[48,49]$. The primary questions for designing RBF neural networks involve two aspects [50]: (1) the construction of a network structure (the hidden layer size and initial parameters); (2) the optimization of all the parameters (centers, radii, and weights). Compared with $\mathrm{BP}$ network, the main difference lies in the use of different functions. In BP network, the hidden layer is sigmoid function, which is a neural network with global approximation. The function is Gaussian basis function in RBF network, which is a neural network with local approximation. Therefore, RBF network can greatly accelerate the learning speed and avoid the local minimum problem, which is suitable for the requirements of timely control and can effectively improve the accuracy, robustness, and selfadaptability of the system.

RBF neural network has three layers: input layer, hidden layer, and output layer. A schematic for an RBF neural network, which is a type of receptive-field neural network, is shown in Figure 1. There are $N$ neurons in the input layer, $J$ neurons in the hidden layer, and $M$ neurons in the output layer. The input layer receives information $\mathrm{x}=\left(x_{1}, x_{2}, \cdots, x_{N}\right)^{T}$ from the environment.

Locally sensitive hidden neurons are usually described by the Gaussian function:

$$
\theta_{j}(X)=e^{-\frac{\left\|X-c_{j}\right\|^{2}}{\sigma_{j}^{2}}},
$$

where $c_{j}$ is the center vector of the $j$ th neuron and $\sigma^{2}$ denotes its radius.

The output neurons combine information from the hidden layer and calculate the following:

$$
y_{m}(X)=\sum_{j=1}^{J} w_{j m} \theta_{j}(X),
$$

where $w_{j m}$ is the weight of the connection from hidden neuron $j$ to output neuron $\mathrm{m}$, and $y_{m}(X)$ is the output of the $m$ th neuron in the output layer.

4.3. ANP-RBF. First of all, according to the experience and the actual situation of the candidate LSPs, enterprise experts need to score each index of the candidate LSPs, and the sum of each index score and its weight product is the total score. Second, it is easy to train RBF neural network after dimensional conversion of the score data. The building process of ANP-RBF neural network model is shown in Figure 2.

\section{Experimental Testing and Analyses}

5.1. Experimental Data. We select the data of a cruise company for empirical test and analysis, a world-famous large cruise company whose headquarter is located in the United States. Since June 2012, in order to open up the Chinese cruise market, it has set up cruise China branch with Shanghai as its home port. In order to maintain stable relations in the cruise supply chain, it needs to select suitable long-term strategic partners from multiple LSPs for cruise ship supply. Based on the bidding sample data of 12 cruise ship supply LSPs, the score of each index is shown in Table 3 , and the full mark is 10 .

\subsection{Simulation Results and Analysis}

5.2.1. Weight Fixing by ANP. Firstly, we classify the evaluation indexes of LSPs and evaluate the importance of each index from the research results and experience of relevant 


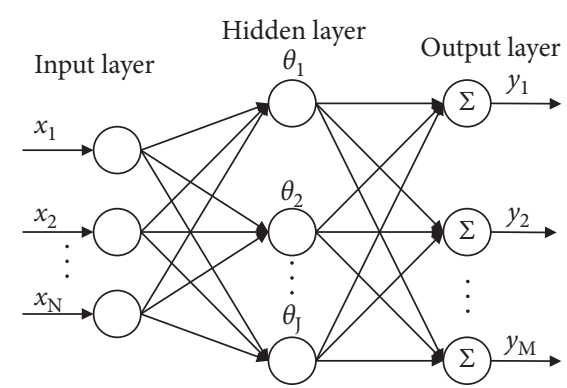

Figure 1: The RFB neural network structure diagram.

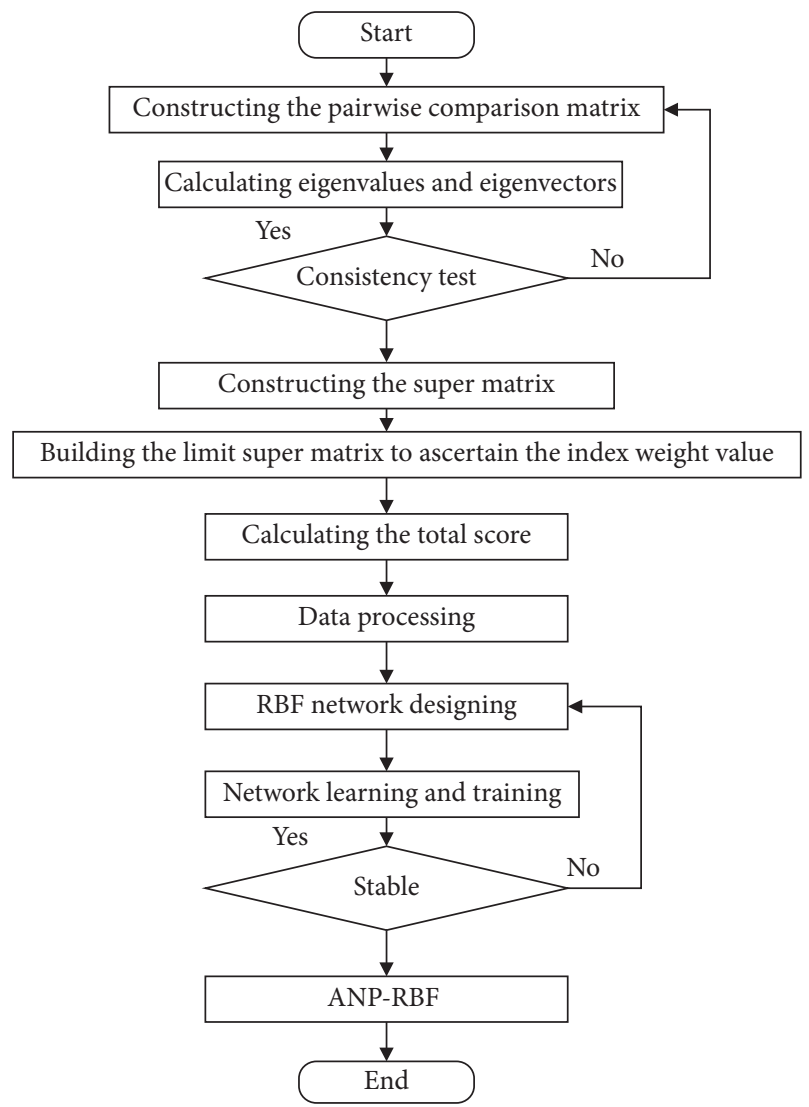

FIGURE 2: Building process of the ANP-RFB neural network model.

experts. Secondly, the internal experts establish an evaluation matrix based on the comprehensive evaluation indexes of the actual situation for the cruise enterprise. Thirdly, we determine the network structure diagram of the evaluation index system and construct the pairwise comparison judgment matrix. The judgment matrix of major criteria with respect to business level (B1) and information level (B2) is shown in Tables 4 and 5 . We establish the network structure diagram of the evaluation index system by using Super Decisions 2.10 and construct element groups, elements, and related relations shown in Figure 3.

As can be seen from Table 4, the business level is higher than the collaborative ability, and the competitiveness is higher than the collaborative ability. Then, we establish the other judgment matrix of major criteria one by one according to this step and establish the judgment matrix for the target layer based on the subcriteria, as shown in Table 6 .
TABLE 3: The score of each index for candidate LSPs.

\begin{tabular}{lccccccccccc}
\hline Providers & C1 & C2 & C3 & C4 & C5 & C6 & C7 & C8 & C9 & C10 & C11 \\
\hline 1 & 7 & 8 & 6 & 6 & 7 & 6 & 8 & 9 & 6 & 4 & 7 \\
2 & 8 & 9 & 7 & 8 & 6 & 8 & 7 & 7 & 6 & 5 & 6 \\
3 & 8 & 8 & 8 & 5 & 7 & 7 & 6 & 5 & 5 & 3 & 6 \\
4 & 9 & 8 & 7 & 8 & 8 & 7 & 7 & 6 & 6 & 3 & 7 \\
5 & 8 & 7 & 6 & 7 & 8 & 7 & 6 & 8 & 6 & 4 & 7 \\
6 & 8 & 7 & 8 & 5 & 6 & 5 & 6 & 6 & 7 & 5 & 6 \\
7 & 6 & 7 & 7 & 6 & 5 & 6 & 7 & 6 & 5 & 4 & 7 \\
8 & 5 & 4 & 5 & 4 & 5 & 6 & 6 & 6 & 3 & 4 & 3 \\
9 & 7 & 6 & 7 & 6 & 6 & 5 & 7 & 5 & 7 & 3 & 7 \\
10 & 8 & 3 & 4 & 6 & 3 & 3 & 7 & 3 & 3 & 4 & 5 \\
11 & 8 & 7 & 8 & 7 & 6 & 7 & 6 & 6 & 5 & 3 & 4 \\
\hline
\end{tabular}

TABle 4: The judgment matrix of major criteria with respect to business level (B1).

\begin{tabular}{cccc}
\hline B1 & B1 & B2 & B4 \\
\hline B1 & 1 & 5 & 3 \\
B2 & $1 / 5$ & 1 & $1 / 3$ \\
B4 & $1 / 3$ & 3 & 1 \\
\hline
\end{tabular}

TABle 5: The judgment matrix of major criteria with respect to information level (B2).

\begin{tabular}{lcccc}
\hline B2 & B1 & B2 & B3 & B4 \\
\hline B1 & 1 & 5 & $1 / 3$ & $1 / 4$ \\
B2 & $1 / 5$ & 1 & $1 / 6$ & $1 / 7$ \\
B3 & 3 & 6 & 1 & $1 / 5$ \\
B4 & 4 & 7 & 2 & 1 \\
\hline
\end{tabular}

In the same way, we get the other second-grade index matrices one by one according to the above methods and use software paired comparison commands to compare the relationships between elements.

Finally, we execute the command of "Priorities" under "Computations" to bring on the global weight of each index, as shown in Table 7.

5.2.2. RBF Training and Validation. Due to the different dimensions of the sample indexes, it is necessary to carry out dimensional transformation. The service price is transformed by (9), and the business level, coordination capacity, and competitiveness are transformed by

$$
\begin{aligned}
y_{i} & =\frac{\max \left\{x_{i}\right\}-x_{i}}{\max \left\{x_{i}\right\}-\min \left\{x_{i}\right\}}, \\
y_{i} & =\frac{x_{i}-\min \left\{x_{i}\right\}}{\max \left\{x_{i}\right\}-\min \left\{x_{i}\right\}} .
\end{aligned}
$$

After dimensional conversion of the data of the LSPs in Table 3, we get the evaluation results of each provider according to the weight results of each index above, as shown in Table 8 . Hence, we can see that the logistics service provider 9 is the best one for the cruise company.

Using MATLAB software, we take the score of 10 element indexes as the input layer of RBF, the score of LSPs as 


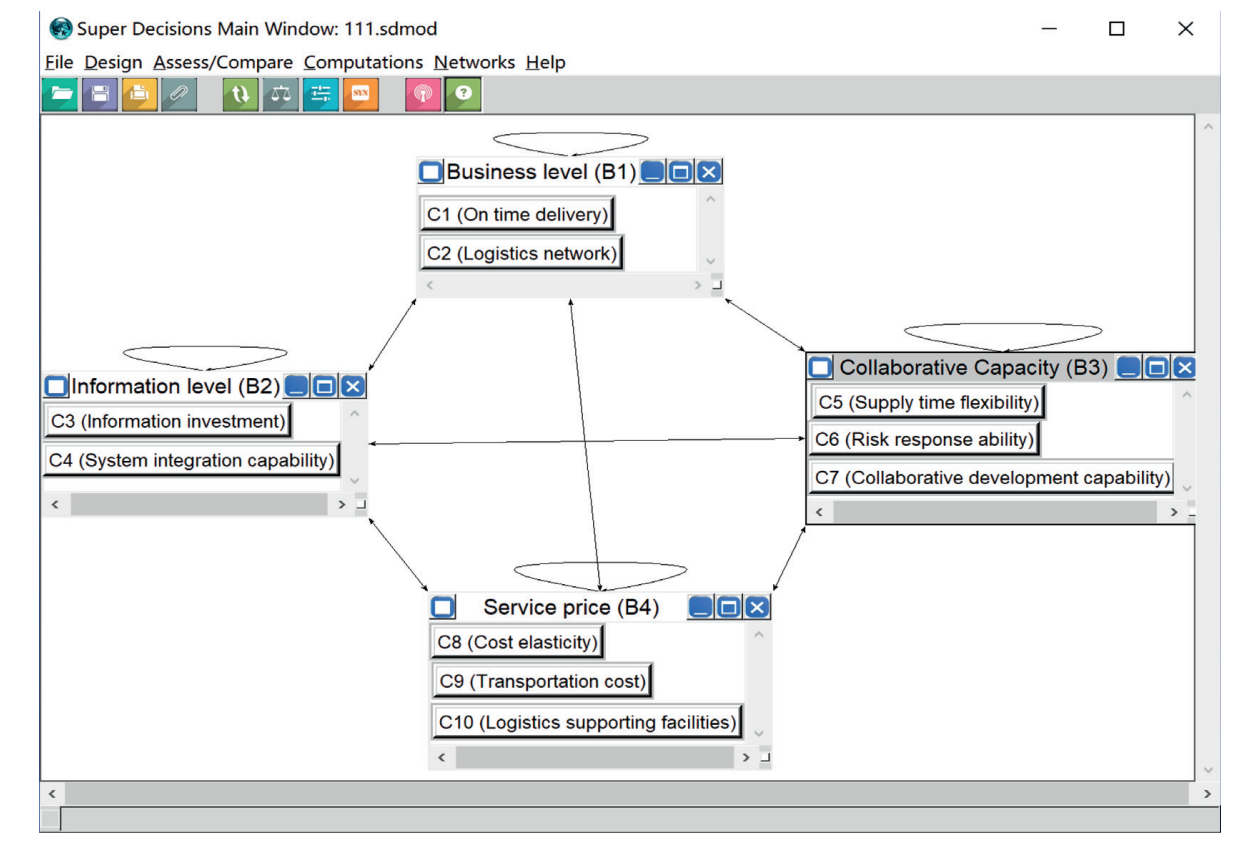

FIGURE 3: The network structure diagram of the evaluation index system for cruise ship supply LSPs.

TABLE 6: The judgment matrix under risk response ability (C3).

\begin{tabular}{lcc}
\hline $\mathrm{C} 2$ & $\mathrm{C} 1$ & $\mathrm{C} 2$ \\
\hline $\mathrm{C} 1$ & 1 & 5 \\
$\mathrm{C} 2$ & $1 / 5$ & 1 \\
\hline
\end{tabular}

TABLE 7: The weight value of each index.

\begin{tabular}{lcc}
\hline Dimensions & Criteria & Weight value (ANP) \\
\hline Business level (B1) & On-time delivery (C1) & 0.2080 \\
& Logistics network (C2) & 0.2080 \\
Information level (B2) & Information investment (C3) & 0.0184 \\
& System integration capability (C4) & 0.0179 \\
Collaborative capacity (B3) & Supply time flexibility (C5) & 0.1018 \\
& Risk response ability (C6) & 0.0611 \\
Service price (B4) & Collaborative development capability (C7) & 0.0516 \\
& Cost elasticity (C8) & 0.0443 \\
& Transportation cost (C9) & 0.1568 \\
\hline
\end{tabular}

TABLE 8: The evaluation results of LSPs.

\begin{tabular}{lccccccccccc}
\hline Provider & 1 & 2 & 3 & 4 & 5 & 6 & 7 & 8 & 9 & 10 & 11 \\
\hline Score & 0.526 & 0.600 & 0.739 & 0.738 & 0.634 & 0.262 & 0.693 & 0.599 & 0.799 & 0.644 & 0.712 \\
\hline
\end{tabular}

the output layer, and the data after dimensional processing as the training sample. Then, we get the network fitting comprehensive evaluation results of LSPs, as shown in Figure 4.

As can be seen from Figure 4, after dimensional processing of different types of data, we use RBF neural network model to input, and the mean square error (MSE) is 0.0043 . The result value is close to the fitted value, which shows that the effect is very good. The RBF neural network evaluation is used to verify and fit the training data and extract the hidden knowledge and rules, which can reduce the influence of subjective factors in the process of supplier evaluation. Therefore, the learning speed is fast, the error is small, and the method can better solve the evaluation problem of cruise ship LSPs.

On the basis of the above, we apply the trained network to make a comprehensive evaluation of the three new LSPs, 


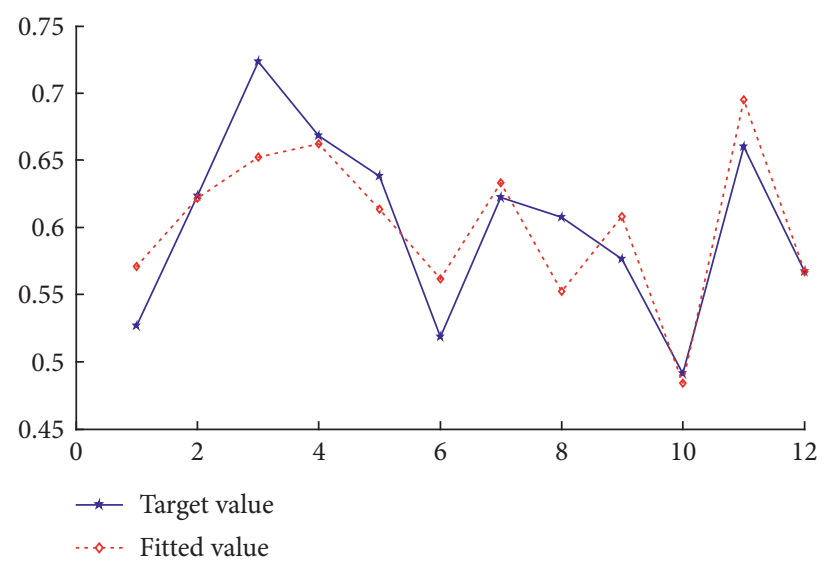

FIgURE 4: Network fitting comprehensive evaluation results.

TABLE 9: The evaluation index score of LSPs.

\begin{tabular}{lcccccccccc}
\hline Provider & C1 & C2 & C3 & C4 & C5 & C6 & C7 & C8 & C9 & C10 \\
\hline 1 & 7 & 5 & 6 & 7 & 8 & 6 & 4 & 7 & 6 & 7 \\
2 & 7 & 6 & 6 & 8 & 7 & 6 & 8 & 9 & 9 \\
3 & 6 & 5 & 7 & 8 & 7 & 6 & 6 & 7 & 6 \\
\hline
\end{tabular}

TABLE 10: The comprehensive score results of cruise ship supply LSPs.

\begin{tabular}{lccr}
\hline Provider & 1 & 2 & 3 \\
\hline Target value & 0.5515 & 0.1496 & 0.3869 \\
RBF fitted value & 0.5495 & 0.1488 & 0.3764 \\
Absolute error & 0.0020 & 0.0008 & 0.0105 \\
\hline
\end{tabular}

and the scores are shown in Table 9. We obtain the target value through ANP model and the comprehensive evaluation results of RBF neural network method, as shown in Table 10.

As can be seen from Table 10, the target values are dimensionless and weighted according to the weights of each index and the scores of 3 groups of LSPs. The first logistics service provider is the best one; its value is 0.5515 . The RBF fitted value is very close to the target value of three LSPs, and the maximum absolute error is 0.0105 . Therefore, the trained RBF neural network model has better learning effect and nonlinear mapping ability for LSPs evaluation.

The above analysis shows that the solution algorithm of ANP-RBF model is incremental algorithm, and the model has good scalability, which increases the dynamic of evaluation.

5.3. Comparison Analysis. AHP method can be also used to solve the problem of multicriteria decision-making $[10,11]$. It is applied in many studies of LSPs evaluation, and we will not explain its principle and steps in detail here. We construct the judgment matrix, as shown in Table 11 and Table 12 .

Then, using Super Decisions 2.10, we can get the weight value of each index by AHP method, and the comparison results are as shown in Table 13 and Figure 5.
As can be seen from Table 10 and Figure 5, ANP method considers the relationship of interdependence and feedback between the criteria and the specific indexes in the criteria. Compared with the weights using AHP method, there are two main differences: First, the weight of business level in the criteria layer is increased, replacing output service price as the most important factor in the evaluation of LSPs; second, the weight of transportation cost and logistics supporting facilities is significantly higher than that of cost elasticity in the criteria.

In contrast, the weight value using ANP method is reasonable. In the four dimensions of LSPs for cruise ship supply, business level is the basis of the others. Meanwhile, business level is also affected by the feedback and influence of service price and collaborative capacity; its weight value is higher than the other three. Due to the difference in standards and examination procedures among countries, the weight value of demand response timeliness will be lower. We can conclude that ANP method is more suitable for complex system problems such as LSPs for cruise ship supply and it is more realistic.

5.4. Managerial Insights. Cruise ship supply logistics has received considerable attention from operational managers and top management decision makers. It is closely related to economics, environmental regulation, and strategy. The case 
TABLE 11: The judgment matrix of major criteria with respect to information level (B2).

\begin{tabular}{lcccc}
\hline B2 & B1 & B2 & B3 & \\
\hline B1 & 1 & 5 & $1 / 3$ & $1 / 4$ \\
B2 & $1 / 5$ & 1 & $1 / 6$ & $1 / 7$ \\
B3 & 3 & 6 & 1 & $1 / 5$ \\
B4 & 4 & 7 & 2 & 1 \\
\hline
\end{tabular}

TABLE 12: The judgment matrix of subcriteria with respect to business level (B1).

\begin{tabular}{lcc}
\hline $\mathrm{B} 1$ & $\mathrm{C} 1$ & $\mathrm{C} 2$ \\
\hline $\mathrm{C} 1$ & 1 & 5 \\
$\mathrm{C} 2$ & $1 / 5$ & 1 \\
\hline
\end{tabular}

TABLE 13: The weight value comparison of AHP and ANP.

\begin{tabular}{lccc}
\hline Dimensions & Criteria & Weight value (AHP) & Weight value (ANP) \\
\hline \multirow{2}{*}{ Business level (B1) } & On-time delivery (C1) & 0.121 & 0.2080 \\
& Logistics network (C2) & 0.024 & 0.2080 \\
Information level (B2) & Information investment (C3) & 0.012 & 0.0184 \\
& System integration capability (C4) & 0.036 & 0.0179 \\
Collaborative capacity (B3) & Supply time flexibility (C5) & 0.165 & 0.1018 \\
& Risk response ability (C6) & 0.104 & 0.0611 \\
Service price (B4) & Collaborative development capability (C7) & 0.044 & 0.0516 \\
& Cost elasticity (C8) & 0.333 & 0.0443 \\
& Transportation cost (C9) & 0.050 & 0.1568 \\
\hline
\end{tabular}

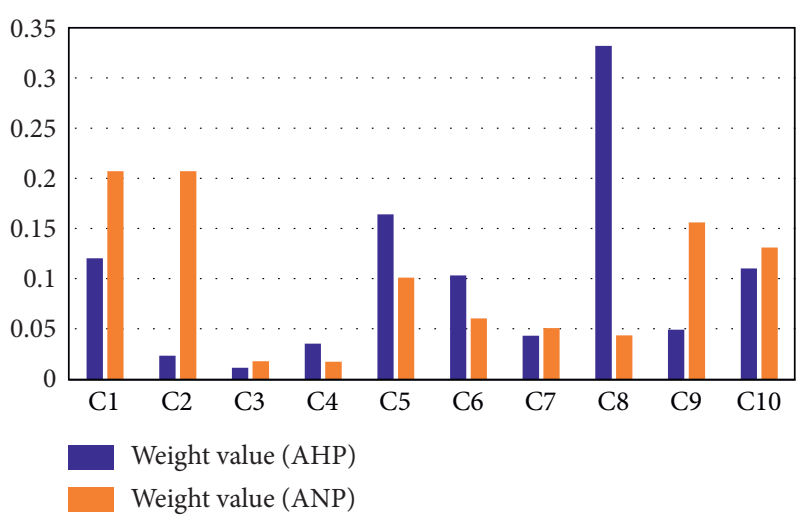

Figure 5: Network fitting comprehensive evaluation results.

studied in this paper has significant managerial implications. In this study, the ANP-RBF methodology adopted provides managers, responsible for selecting cruise ship supply LSPs for their organization, with insights about the various factors that need to be considered while selecting LSPs. The selected approach also aids them in prioritizing the criteria. Managers can utilize the hierarchical structure of adopted LSPs evaluation methodology suggested in this study to rank LSPs on the basis of various factors/criteria.

The sensitivity analysis performed in this study also analyzes the effect of changing the weights of the main criteria on the ranking of logistics providers for the cruise company, which will help managers in decision-making. This approach will also help managers in dividing the complex problem into simpler hierarchy.

\section{Conclusions}

In this paper, we put forward an evaluation model based on ANP-RBF method to study the evaluation of cruise ship LSPs. Firstly, we use ANP model to ascertain the weights of indexes. Secondly, we apply the RBF neural network to verify and fit the data. This method extracts the hidden knowledge and rules, and it can avoid the influence of subjective factors in the decision-making process. Through case study, we can see that on-time delivery and logistics network are the important criteria for evaluation of cruise ship supply LSPs. Hence, it is necessary to build a supporting collection and distribution logistics network to realize the information data exchange of cruise ship supplies procurement, transportation, and distribution in cruise ship supply service chain. As a result, it can improve the efficiency and reliability of the supply chain and effectively reduce the inventory of cruise companies. This is the real value of logistics network optimization and construction, and it is also the direction for the further development of China's cruise ship supply system; it has practical significance for the evaluation of cruise ship supply LSPs to China cruise lines. However, the factors affecting the supply logistics of cruise ships are complex, and the relevant indexes are qualitative and are not quantified. Therefore, this has a certain impact on the evaluation of LSPs. Besides, due to the influence of cruise port supporting infrastructure and related policies, local cruise ship supply companies are uneven, so it may be more complicated in practical application.

The proposed methodology has limitations though. First of all, ANP relies heavily on expert opinions, which may be 
biased by the subjectivity and transitivity associated with the decision maker. Therefore, there is a need for a better aggregation methodology. For example, the same problem can be analyzed with ANP-RBF, so that the vagueness of the opinion of the decision maker can be taken care of. On top of that, a user-friendly interface needs to be developed to simplify the ANP calculations so as to use the proposed approach in real-life problems more easily, so we use Super Decisions software to solve it. The outcome of the model presented is purely dependent on the inputs provided by the experts of the cruise company. Thus, further refinement of the model can be done by carrying out additional field studies or by conducting surveys with other organizations.

Furthermore, the cruise ship is a special kind of vessel for international navigation. In the broad sense, cruise ship supplies are basically the same as ship materials, which can be divided into fuel, materials, consumables, and duty-free goods, and their procurement would be profoundly different. The current research needs to be further explored and refined, and the score of pairwise comparison matrix can be further standardized to avoid human subjective influence to the greatest extent. It can establish scoring rules for specific cruise ship supplies and relative importance of each index to guide evaluators to make objective evaluation.

\section{Data Availability}

The data used to support the findings of this study are included within the article.

\section{Conflicts of Interest}

The authors declare that they have no conflicts of interest.

\section{References}

[1] S. Ros Chaos, A. A. Pallis, S. Saurí Marchán, D. Pino Roca, and A. Sánchez-Arcilla Conejo, Economies of Scale in Cruise Shipping, Maritime Economics and Logistics, Rotterdam, Netherlands, 2020.

[2] J. Esteve-Perez and A. Garcia-Sanchez, "Cruise market: stakeholders and the role of ports and tourist hinterlands," Maritime Economics \& Logistics, vol. 17, no. 3, pp. 371-388, 2015.

[3] G. Michaël and D. Michaël, "An analysis of the CSR portfolio of cruise shipping lines," Research in Transportation Business \& Management, vol. 8, Article ID 100615, 2020.

[4] G. W. Y. Wang, A. A. Pallis, and T. E. Notteboom, "Incentives in cruise terminal concession contracts," Research in Transportation Business \& Management, vol. 13, pp. 36-42, 2014.

[5] S. Véronneau and J. Roy, "RFID benefits, costs, and possibilities: the economical analysis of RFID deployment in a cruise corporation global service supply chain," International Journal of Production Economics, vol. 122, no. 2, pp. 692-702, 2009.

[6] S. Véronneau, J. Roy, and M. Beaulieu, "Cruise ship suppliers: a field study of the supplier relationship characteristics in a service supply chain," Tourism Management Perspectives, vol. 16, pp. 76-84, 2015.

[7] S. Véronneau and J. Roy, "Global service supply chains: an empirical study of current practices and challenges of a cruise line corporation," Tourism Management, vol. 30, no. 1, pp. 128-139, 2009.

[8] S. Véronneau and Y. Cimon, "Maintaining robust decision capabilities: an integrative human-systems approach," Decision Support Systems, vol. 43, no. 1, pp. 127-140, 2007.

[9] D. Vukonic, T. Bielic, and A. Russo, "Organizational factors in management of "Mega Cruise Ships" from crowd management control aspect," Scientific Journal of Maritime Research, vol. 30, pp. 58-66, 2016.

[10] J. Wang, J. B. Yin, R. U. Khan, S. Q. Wang, and T. Zheng, "A study of inbound logistics mode based on JIT production in cruise ship construction," Sustainability, vol. 13, no. 1588, p. 1588, 2021.

[11] C.-A. Chen, "How can Taiwan create a niche in Asia's cruise tourism industry?" Tourism Management, vol. 55, pp. 173183, 2016.

[12] H. William, X. W. Xu, and K. D. Prasanta, "Multi-criteria decision making approaches for supplier evaluation and selection: a Literature Review," European Journal of Operational Research, vol. 202, pp. 16-24, 2010.

[13] J.-F. Ding, J.-F. Kuo, and W.-H. Tai, "Using fuzzy AHP method to evaluate key competency and capabilities of selecting middle managers for global shipping logistics service providers," Pomorstvo, vol. 33, no. 1, pp. 3-10, 2019.

[14] V. Jain and S. A. Khan, "Application of AHP in reverse logistics service provider selection: a case study," International Journal of Business Innovation and Research, vol. 12, no. 1, pp. 94-119, 2017.

[15] N. Choudhury, R. D. Raut, B. B. Gardas, M. G. Kharat, and S. Ichake, "Evaluation and selection of third party logistics services providers using data envelopment analysis: a sustainable approach," International Journal of Business Excellence, vol. 14, no. 4, pp. 427-453, 2018.

[16] E. Celik, M. Erdogan, and A. T. Gumus, "An extended fuzzy TOPSIS-GRA method based on different separation measures for green logistics service provider selection," International Journal of Environmental Science and Technology, vol. 13, no. 5, pp. 1377-1392, 2016.

[17] K. Chen, X. Yu, and L. Yang, "GI-TOPSIS based on combinational weight determination and its application to selection of reverse logistics service providers," Journal of Grey System, vol. 25, no. 3, pp. 16-33, 2013.

[18] K. Seongtae, M. Ramkumar, and N. Subramanian, "Logistics service provider selection for disaster preparation: a sociotechnical systems perspective," Annals of Operations Research, vol. 283, no. 1-2, pp. 1259-1282, 2019.

[19] M. Abdel-Baset, V. Chang, A. Gamal, and F. Smarandache, "An integrated neutrosophic ANP and VIKOR method for achieving sustainable supplier selection: a case study in importing field," Computers in Industry, vol. 106, pp. 94-110, 2019.

[20] S. Wang, T. Wang, X. Qu, Z. Liu, and S. Jin, "Liner ship fleet deployment with uncertain demand," Transportation Research Record: Journal of the Transportation Research Board, vol. 2409, no. 1, pp. 49-53, 2014.

[21] T. Wang, Q. Meng, S. Wang, and Z. Tan, "Risk management in liner ship fleet deployment: a joint chance constrained programming model," Transportation Research Part E: Logistics and Transportation Review, vol. 60, pp. 1-12, 2013.

[22] R. M. Budiartha and I. P. A. Adnyana, "The development of marine transportation system in supporting sustainable tourism-case study: nusa Penida Island, Bali Indonesia," 
Journal of Sustainable Development, vol. 9, no. 4, pp. 89-95, 2016.

[23] H. Li, Z. K. He, Q. Li, and Q. B. Sun, "Applications of the improved TOPSIS decision-making method in the supplier selection," Mathematics in Practice and Theory, vol. 46, no. 16, pp. 93-101, 2016.

[24] H. Danai, S. Hashemnia, R. Ahmadi, and S. H. Bazazzadeh, "Application of fuzzy ANP method to select the best supplier in the supply chain," International Journal of Operational Research, vol. 35, no. 1, pp. 1-19, 2019.

[25] Ö. Uygun, H. Kaçamak, and Ü. A. Kahraman, “An integrated DEMATEL and Fuzzy ANP techniques for evaluation and selection of outsourcing provider for a telecommunication company," Computers \& Industrial Engineering, vol. 86, pp. 137-146, 2015.

[26] B. Guo, J. P. Liang, and Y. P. Liu, "Supplier evaluation and selection of the research based on ANP-TOPSIS in green supply chain," Science and Technology Management Research, vol. 11, pp. 229-234, 2015.

[27] A. Dargi, A. Anjomshoae, M. R. Galankashi, A. Memari, and M. B. M. Tap, "Supplier selection: a FUZZY-ANP approach," Procedia Computer Science, vol. 31, pp. 691-700, 2014.

[28] N. R. Galo, P. C. C. Ribeiro, R. C. Mergulhão, and J. G. V. Vieira, "Selección de proveedor de servicios logísticos: alineación entre criterios e indicadores," Innovar, vol. 28, no. 69 , pp. 55-70, 2018.

[29] J. Fan, X. Liu, M. Wu, and Z. Wang, "Green supplier selection with undesirable outputs DEA under Pythagorean fuzzy environment," Journal of Intelligent \& Fuzzy Systems, vol. 37, no. 2, pp. 2443-2452, 2019.

[30] B. Patricija, T. S. Danijela, and Z. Eva, "A distance-based AHP-DEA super-efficiency approach for selecting an electric bike sharing system provider: one step closer to sustainability and a win-win effect for all target groups," Sustainability, vol. 13, no. 549, p. 549, 2021.

[31] L. Huang and J. Yang, "An optimization approach to a twostage replenishment strategy in cruise liner operations under dynamic demand," Journal of the Operational Research Society, pp. 1-12, 2020.

[32] S. Ghosh, L. H. Lee, and S. H. Ng, "Bunkering decisions for a shipping liner in an uncertain environment with service contract," European Journal of Operational Research, vol. 244, no. 3, pp. 792-802, 2015.

[33] H. P. Paryhiban, Z. Abdul, and P. G. Chintamani, "A multi criteria decision making approach for supplier selection," Procedia Engineering, vol. 38, pp. 2312-2328, 2012.

[34] K. M. Mohamed, F. Kjetil, M. Frank, and L. Elizabeth, "Analyzing different designs of liner shipping feeder networks: a case study," Transportation Research Part E: Logistics and Transportation Review, vol. 134, 2020.

[35] L. Huang and J. Yang, "Location-distribution of cruise ship supply logistics distribution centre considering time window," Systems Science \& Control Engineering, vol. 7, no. 1, pp. 338-345, 2019.

[36] Y. Wang, S. G. Peng, X. S. Zhou, M. Mahmoudi, and L. Zhen, "Green logistics location-routing problem with eco-packages," Transportation Research Part E: Logistics and Transportation Review, vol. 143, pp. 102-118, 2020.

[37] Y. Wang, Y. Y. Yuan, X. Y. Guan et al., "Collaborative twoechelon multicenter vehicle routing optimization based on state-space-time network representation," Journal of Cleaner Production, vol. 258, pp. 0958-6526, 2020.

[38] Y. Wang, X. Ma, Z. Li, Y. Liu, M. Xu, and Y. Wang, "Profit distribution in collaborative multiple centers vehicle routing problem," Journal of Cleaner Production, vol. 144, pp. 203219, 2017.

[39] L. Zhen, Y. Wu, S. Wang, and G. Laporte, "Green technology adoption for fleet deployment in a shipping network," Transportation Research Part B: Methodological, vol. 139, pp. 388-410, 2020.

[40] K. F. David, D. Guy, and R. Stefan, "Integrated liner shipping network design and scheduling," Transportation Science, vol. 54, no. 2, pp. 512-533, 2020.

[41] C. Marielle, H. Erik, P. David, S. David, and V. Charlotte, "Liner shipping network design," European Journal of Operational Research, vol. 286, no. 1, pp. 1-20, 2020.

[42] M. Erkoc, E. T. Iakovou, and A. E. Spaulding, "Multi-stage onboard inventory management policies for food and beverage items in cruise liner operations," Journal of Food Engineering, vol. 70, no. 3, pp. 269-279, 2005.

[43] M. Bennett, "Competing with the sea," Performance Research, vol. 21, no. 2, pp. 50-57, 2016.

[44] Y. M. Bandara and H.-O. Nguyen, "Influential factors in port infrastructure tariff formulation, implementation and revision," Transportation Research Part A: Policy and Practice, vol. 85, pp. 220-232, 2016.

[45] J. Qiao, X. Meng, and W. Li, "An incremental neuronalactivity-based RBF neural network for nonlinear system modeling," Neurocomputing, vol. 302, pp. 1-11, 2018.

[46] A. Bielecki and M. Wójcik, "Hybrid system of ART and RBF neural networks for online clustering," Applied Soft Computing, vol. 58, pp. 1-10, 2017.

[47] X. Li and Y. Sun, "Application of RBF neural network optimal segmentation algorithm in credit rating," Neural Computing and Applications, 2020.

[48] F. Cheshmberah, H. Fathizad, G. A. Parad, and S. Shojaeifar, "Comparison of RBF and MLP neural network performance and regression analysis to estimate carbon sequestration," International Journal of Environmental Science and Technology, vol. 17, no. 9, pp. 3891-3900, 2020.

[49] Q. Liu, P. Sun, X. Fu et al., "Comparative analysis of BP neural network and RBF neural network in seismic performance evaluation of pier columns," Mechanical Systems and Signal Processing, vol. 141, 2020.

[50] H. Wei, W. X. Xie, and J. H. Pei, "An incremental learning algorithm for the hybrid RBF-BP network classifier," EURASIP Journal on Advances in Signal Processing, vol. 2016, no. 1, pp. 1-15, 2016. 